\title{
Matemática: contextualização, limites socioculturais e ambientais de sua aplicação no cotidiano discente
}

Rosineide Xavier Figueiredo Instituto de Educação, Ciência e Tecnologia da Bahia (IFBA) - Campus Vitória da Conquista, BA -Brasil rose.xf02@gmail.com

Milton Ferreira da Silva Júnior Departamento de Ciências Agrárias e Ambientais da Universidade Estadual de Santa Cruz - Ilhéus, BA -Brasil. notlimf@gmail.com

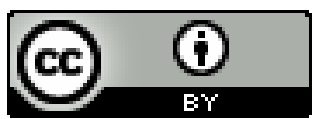

EDUCAÇÃO: Teoria e Prática, Rio Claro, SP, Brasil - elSSN: 1981-8106 Está licenciada sob Licença

\section{Creative Common}

\section{Resumo}

A problemática ambiental tem sido objeto de estudo e preocupação da sociedade contemporânea. Por sua vez, a educação transforma o modo de pensar e de agir dos sujeitos por meio de um ensino contextualizado e interdisciplinar, despertando neles o senso crítico. Levando isso em consideração, esta pesquisa estudou especificamente a Matemática, ciência do raciocínio lógico e instrumento para que o homem interfira na construção de uma sociedade pautada na interpretação da natureza para uma vida sustentável, e também buscou investigar os limites socioculturais da implantação das práticas ambientalistas na contextualização do ensino da referida disciplina para o alcance do que Capra (1996) chama de Alfabetização Ecológica. A pesquisa foi realizada com alunos das primeiras e quartas séries dos Cursos de Modalidade Integrada do Instituto Federal de Educação, Ciência e Tecnologia da Bahia (IFBA), campus de Vitória da Conquista, durante o mês de dezembro de 2011. A investigação foi quantitativa, com aplicação de questionário, e os dados coletados permitiram alcançar resultados que levantaram propostas de mudanças no ensino e na aprendizagem não só da Matemática, mas, também, das demais disciplinas, no sentido de contribuir para o desenvolvimento de atitudes e valores do comportamento humano.

Palavras-chave: Alfabetização Ecológica. Ensino Contextualizado. Interdisciplinar. Matemática. Problemática ambiental.

\section{Mathematics: contextualization, sociocultural and environmental limits of its application in the students' everyday lives}

\begin{abstract}
The environmental issues have been the subject of study and concern in the contemporary society. In its turn, education changes the ways of thinking and acting of the individuals through a contextualized and interdisciplinary teaching, awakening them to a critical sense.
\end{abstract}


Taking this into account, this research studied specifically mathematics, which is not only the logical reasoning science but also an instrument which can be used by man to interfere in the building of a society based on his interpretation of nature in order to achieve a sustainable life. It also sought to inquire into the social and cultural limits of the introduction of the environmental practice in Mathematics teaching in order to reach what Capra (1969) calls "Ecological Literacy". The survey was carried out with first and fourth-grade students of the Integrated Mode Courses in the Federal Institute of Education, Science and Technology of Bahia (IFBA), campus Vitoria da Conquista, during the month of December 2011. As it was a quantitative research, a questionnaire was applied and the collected data made it possible to reach results that generated proposals for changes in teaching and learning not only mathematics but also other disciplines, aiming to contribute to the development of attitudes and values concerning the human behavior.

Keywords: Ecological Literacy. Real Context Teaching. Interdisciplinary. Mathematics. Environmental issues.

\section{Matemáticas: contextualización, límites socioculturales y ambientales de su aplicación en el cotidiano discente}

\section{Resumen}

La problemática ambiental ha sido objeto de estudio y preocupación de la sociedad contemporánea. A su vez, la educación transforma el modo de pensar y de actuar de los sujetos por medio de una enseñanza contextualizada e interdisciplinar, despertando en ellos el sentido crítico. Tomando esto en consideración, esta investigación estudió específicamente las Matemáticas, ciencia de raciocinio lógico e instrumento para que el hombre interfiera en la construcción de una sociedad pautada en la interpretación de la naturaleza para una vida sostenible, y también buscó investigar los límites socioculturales de la implantación de las prácticas ambientalistas en la contextualización de la enseñanza de la referida disciplina para el alcance de lo que Capra (1996) llama de Alfabetización Ecológica. La investigación se realizó con alumnos de los primeros y cuartos años de los Cursos de Modalidad Integrada del Instituto Federal de Educación, Ciencia y Tecnología de Bahia (IFBA), campus de Vitória da Conquista, durante el mes de diciembre de 2011. La investigación fue cuantitativa, con aplicación de cuestionario, y los datos recolectados permitieron alcanzar resultados que levantaron propuestas de cambios en la enseñanza y en el aprendizaje no solo de Matemáticas, sino también de las demás disciplinas, en el sentido de contribuir para el desarrollo de actitudes y valores del comportamiento humano. 
Palabras clave: Alfabetización Ecológica. Enseñanza Contextualizada. Interdisciplinar. Matemáticas. Problemática ambiental.

1. Introdução

A educação é uma prática de cunho social que implica na interação do homem com o seu contexto socioeconômico, político e cultural, interferindo em seus processos de aprendizagem. Então, é nesse espaço que o indivíduo pode adquirir uma consciência ecológica com o desafio de harmonizar objetivos socioeconômicos e ambientais e redefinir os padrões de uso de recursos naturais.

Assim sendo, a escola passa a ser "um espaço/mundo do questionamento, da mediação/confronto entre teorias e práticas, da recriação de teorias e práticas [...]" (PRADO; DAMASCENO, 2007, p. 25), onde o indivíduo realiza suas aspirações e reflete sobre o fazer, como fazer e o que fazer em certos contextos e limites socioculturais. Dessa forma, é necessário que haja a exploração e atualização dos aprendizados. O professor, segundo Laudares (2004), precisa estimular o estudante a propor soluções, a levantar hipóteses, a organizar, a comparar, a analisar os seus resultados e a associá-los com o espaço no qual está inserido. Como diz Moretto (2010, p.46) “a construção do conhecimento é resultado de uma interação social, via linguagem e imersão em determinado contexto cultural, com o objetivo da inserção do sujeito em seu meio".

Entretanto, a realidade do ensino atual, baseada na transmissão compartimentada do conhecimento, dificulta a interação com a realidade social. Surge um novo paradigma, o qual, segundo Capra (1996), sugere que a análise do todo é imprescindível, ou seja, cada componente de um ecossistema tem importância representativa dentro do contexto de sistemas vivos, constituindo o que ele chama de redes.

Na ciência, essa descoberta foi bastante significativa, pois mostra que não existe nenhum fenômeno mais importante do que outro, todos se completam formando uma estrutura única de objetividade científica. Os inúmeros avanços na Matemática diminuíram a imprecisão do modelamento dos fenômenos da natureza. Capra (1996) declarou que vários modelos de sistemas só foram formulados quando novas ferramentas matemáticas ficaram disponíveis, tornando possível a resolução de equações complexas. Assim, as inúmeras descobertas contribuíram para o aparecimento de novas teorias matemáticas a exemplo do cálculo diferencial, topologia, geometria fractal. 
Essa geometrização dos problemas matemáticos deu à ciência uma infinitude de aplicações em todos os campos, pois o aparecimento de novos fenômenos contribuiu para o avanço na teoria matemática. Isso mostra que a Matemática da Complexidade não representa um conjunto de fórmulas e expressões escandalosas que impedem o seu entendimento e aplicação de maneira objetiva, mas, sim, uma importância para a resolução de problemas das mais diversas áreas. Por isso, "contextualizar a matemática é essencial para todos", afirma D’Ambrósio (1996, p. 115).

Além disso, a contextualização da Matemática se faz necessária, porque muitos dos problemas em seu ensino são oriundos tanto da forma isolada como é trabalhada como de sua própria concepção euclidiana, por vezes hegemônica, na linearidade do seu conhecimento. A Organização Curricular para o Ensino Médio (BRASIL, 2008, p.69) prevê a integração e articulação dos conhecimentos em processo permanente de contextualização. Dessa forma, "é importante que os alunos percebam a Matemática como um conhecimento social e historicamente construído" e não formal e inesperadamente acontecido, pois se trata de uma ciência capaz de mobilizar competências que solucionam problemas em situações apropriadas, de maneira a transferir essa capacidade de resolução de problemas para os acontecimentos de outras áreas do conhecimento e da atividade humana nos limites socioculturais considerados.

O conhecimento matemático é necessário "como instrumento para lidar com situações da vida cotidiana ou, ainda, como forma de desenvolver habilidades de pensamento" (BRASIL, 2000, p.111). Portanto, a contextualização é imprescindível, pois mobiliza competências para solucionar problemas em situações apropriadas, de maneira a transferir essa capacidade para os acontecimentos do mundo social. Assim, os aspectos referentes ao meio ambiente natural e socioeconômicos, políticos e culturais podem ser tratados de maneira contextualizada para se atingir um desenvolvimento que "busca melhorar a qualidade de vida humana, respeitando a capacidade de suporte dos ecossistemas" (DIAS, 2004, p.31).

$\mathrm{Na}$ contextualização dos fatos, o grande desafio é harmonizar objetivos socioeconômicos e ambientais e redefinir padrões de uso de recursos e das finalidades do crescimento, porém, para atingi-lo é necessário que o indivíduo seja ecologicamente alfabetizado ou ecoalfabetizado, como diz Capra (1996), ou seja, compreenda os princípios 
de organização dos ecossistemas.

O trabalho a ser executado pela educação e por outras esferas da sociedade é o fortalecimento dos princípios da ecologia para que eles sejam, sempre, manifestados, pois se observa que a crise ecológica é também uma crise de educação, cujos princípios têm que estar voltados para a sustentabilidade. Orr $(2006$, p.11) ressalta que "o desequilíbrio dos ecossistemas reflete um desequilíbrio anterior da mente, tornando-o uma questão fundamental nas instituições voltadas para o aperfeiçoamento da mente". Nesse contexto, surge a Alfabetização Ecológica que, segundo Mitchell (2009), trabalha educação com o desenvolvimento do indivíduo voltado à formação integral para que ele possa despertar-se no cuidado pelos outros seres vivos e repensar suas atitudes no que se refere às necessidades de sobrevivência.

Para tanto, a importância da vida e da sustentabilidade será absorvida quando, de fato, a escola se comprometer a trabalhar com o ensino e a aprendizagem de habilidades e procedimentos que envolvam formação de valores, transformando as informações e conceitos em conhecimento que trarão benefícios a todos.

Esse trabalho da escola desperta no indivíduo uma amorosidade pela natureza, destaca a importância da sustentabilidade do planeta Terra e desenvolve a Inteligência Naturalista ou Ecológica, que consiste "numa atração pelo mundo natural" (ANTUNES, 1998, p. 62). Ela é uma das sete inteligências, na Teoria das Inteligências Múltiplas de Gardner, que representam um conjunto de habilidades mentais vitais ao pleno desenvolvimento humano.

O aprimoramento dessa inteligência, no sentido da manutenção e preservação do meio ambiente, contribui para que o indivíduo mantenha uma relação inteligente no controle entre cognição, emoções, sentimentos e psicomotricidades para desenvolver e manter sustentabilidade na relação homem natureza. Afinal, "numa visão sistêmica, a Natureza não é algo que está fora do âmbito humano, o mundo na sua integralidade contém de forma entrelaçada o ambiente natural e cultural, sendo o homem um elemento importante de ambos" (NICOLLIER; VELASCO, 2008, p.15-36), ou seja, natureza é parte do ambiente, não elaborada pelo homem, e cultura refere-se ao conhecimento adquirido e empregado socialmente, conforme afirmam Andrade, Soares e Huck (1999). Essa interação mostra, segundo Mitchell (2009), que a inteligência naturalista incorpora a alfabetização cultural como algo relevante para a Alfabetização Ecológica. 
Além disso, o indivíduo, por meio do raciocínio lógico dedutivo, utiliza conceitos, teorias e histórias para explicar os fenômenos naturais. Nesse momento, há interação entre as inteligências naturalista e lógico-matemática, pois usa instrumentos matemáticos na exploração da natureza. A última inteligência, na concepção de Gardner, quando estimulada, elabora na pessoa "novas formas sobre o pensar e uma percepção apurada dos elementos da grandeza, peso, distância, tempo e outros elementos que envolvem nossa ação sobre o ambiente" SANTOS, 2004, s.p.). Assim sendo, as atividades voltadas aos temas ambientais contribuem para interação entre todas as disciplinas, fazendo com que o estudante conheça seu espaço e o seu contexto social, além de influenciar na formação integral e na reflexão de suas atitudes como um indivíduo alfabetizado ecologicamente.

Portanto, a integração das disciplinas em torno de temas voltados aos aspectos socioeconômicos e políticos da comunidade tornará o papel da alfabetização ecológica ainda mais significativo. Nesse aspecto, Orr (1996) coloca que o objetivo da educação é formar a personalidade humana mediante os conhecimentos cognitivo, emocional e psicomotor que são introduzidos em sua mente por meio dos sentimentos associados aos fatos, técnicas e informações discutidas. Por essa razão, segundo Mitchell (2009), há necessidade de formar indivíduos alfabetizados ecológica e cientificamente por meio da pesquisa, despertando a curiosidade, a imaginação e o senso crítico. No caso da Matemática, segundo Laudares (2004), os PCNs buscam relacionar observações do mundo real com representações (esquemas, tabelas, figuras) e essas representações com os conceitos matemáticos, tornando-os relevantes para a ciência e a sociedade.

Os saberes dos diversos campos do conhecimento, por sua vez, podem ser interagidos de forma interdisciplinar, uma prática que "comparecem as disciplinas, as atividades de ensino e de aprendizagem, as concepções de ciência, de realidade" (BICUDO, 2010, p.216). Na realização de projetos ambientalistas com a Matemática, a interação entre as disciplinas deve se transformar num processo em que há construção do conhecimento de forma dinâmica, refletindo na mudança do comportamento, afirmam Leite, Ferreira e Scrich (2009). Nesses projetos, as ações coletivas e cotidianas têm mais ênfase e abrem discussões em torno da temática ambiental, estimulando o exercício da cidadania de forma crítica e consciente.

Na Matemática, essas atividades representam o despertar do raciocínio para uma 
nova linguagem presente no cotidiano. Ela passa a ter um novo tratamento científico, pois a prática interdisciplinar, segundo Luck (2010), promove uma ampliação da visão de mundo e sua complexidade, além de posicionar o homem na realidade e na produção do conhecimento, propiciando a transformação em todos os sentidos. Portanto, "pensar o ensino da Matemática, na atualidade, requer uma reflexão sobre a função social do conhecimento matemático no século XXI [...]" (CRUSOÉ, 2009, p. 51).

\section{$2 \quad$ Material e Métodos}

Este artigo fez parte da pesquisa desenvolvida no Mestrado do Programa de Desenvolvimento Regional e Meio Ambiente (PRODEMA) da UESC, Ilhéus/BA, durante o mês de dezembro de 2011. Ela teve como ponto de partida a busca de possíveis soluções para as questões ambientais por meio da contextualização do ensino da disciplina Matemática, ministrada nos Cursos de Modalidade Integrada que envolvem a formação técnica de nível médio, apresentando disciplinas do núcleo comum e do curso técnico.

A área de estudo é o Instituto Federal de Educação, Ciência e Tecnologia da Bahia (IFBA), campus de Vitória da Conquista, localizada ao sudoeste do estado da Bahia.

Os sujeitos desse estudo foram cento e trinta e um estudantes (131) matriculados nas 1a e 4a séries dos Cursos da Modalidade Integrada no ano letivo de 2011. Eles foram submetidos ao formulário socioeconômico e cultural, com a finalidade de traçar o seu perfil.

O estudo utilizou o método quantitativo com aplicação de questionário estruturado, contendo perguntas de múltipla escolha, o que é adequado para apurar opiniões e atitudes explícitas e conscientes dos participantes. "Eles tratam de probabilidades, associações estatisticamente significantes, importantes para se conhecer uma realidade" (CODATO; NAKAMA, 2006, p. 35), já que o trabalho selecionou uma grande quantidade de informações numéricas representativas de um universo.

O enfoque qualitativo foi usado nas questões em que os participantes tiveram que justificar as respostas dadas. Esse método trabalha com opiniões e enfatiza o subjetivo que "pode levar a resultados objetivos, claros e concisos, desde que o pesquisador ao interpretar os dados dê o sentido "real" que foi transmitido pelos sujeitos pesquisados", enfatizam Codato e Nakama (2006, p.35). Então, o presente estudo completa o quantitativo na interpretação dos dados e vice-versa. O questionário aplicado objetivou detectar as 
características do ensino e da aprendizagem da Matemática em que estão inseridos e a contribuição dela nas questões ambientais.

Como houve quantificação na coleta das informações, então os dados foram tratados pela análise descritiva para garantir a precisão, evitando distorções, pois ela tem por objetivo encontrar fenômenos, expondo-os detalhadamente, classificando-os e interpretando, como atesta Vieira (2002).

Dos cento e trinta e um alunos que responderam às perguntas, 58 são do sexo masculino e 73 do sexo feminino, distribuídos pelas sete turmas que participaram da pesquisa: o primeiro ano dos quatro cursos, Meio Ambiente, Informática, Eletrônica e Eletromecânica, e o quarto ano de todos estes cursos, exceto o de Eletrônica. A idade dos alunos de primeiro ano variou entre 13 e 17 anos e os de quarto ano, entre 17 e 21 anos. Isso mostra, claramente, que a faixa etária dos estudantes está normal para a série cursada. Uma parte deles vem de outras cidades e regiões, atraída pelas ações do instituto que são aplicadas no desenvolvimento de soluções técnicas e tecnológicas estendidas à comunidade, ações estas que preparam o aluno para a vida a partir de uma concepção de sociedade, trabalho, cultura, educação, tecnologia e ser humano.

\section{Resultados e Discussão}

Por apresentar uma linguagem precisa e formal, a matemática exige uma prática constante e permite uma argumentação concisa e universal. Mesmo sendo abstrata, essa disciplina se originou a partir da necessidade diária do homem, ao longo da história das civilizações. Tendo esse foco como base, foi perguntado aos alunos se eles já utilizaram a Matemática para resolver os problemas do seu dia a dia, o que pode ser visualizado na Figura 1 que 109 discentes (cerca de 83,2\%) disseram que sim e 22 (cerca de 19,8\%) disseram que não.

Os alunos que já utilizaram a Matemática para resolver os problemas do dia a dia, citaram algumas situações, a saber:

Distância de um local a outro, contas de porcentagem, tempo de estudo e lazer, cobrar dívidas, fatura de cartão e parcela de alguma loja, tamanho de móveis, dividir um alimento, compra em supermercado, planejar orçamento doméstico, administrar e manipular o dinheiro na loja para calcular o desconto do produto, tamanho de cada parte da peça de tricô, diferenciar horários adversos em relógios diferentes, relacionar dinheiro com o que devo gastar, orçamento de trabalho 
escolar, gasto na escola, juro de cartão de crédito, pagamentos, receita de culinária, promoção, áreas de alguns espaços, divisão de itens entre pessoas, arquitetura residencial, renda familiar (alimentos, produtos, energia).

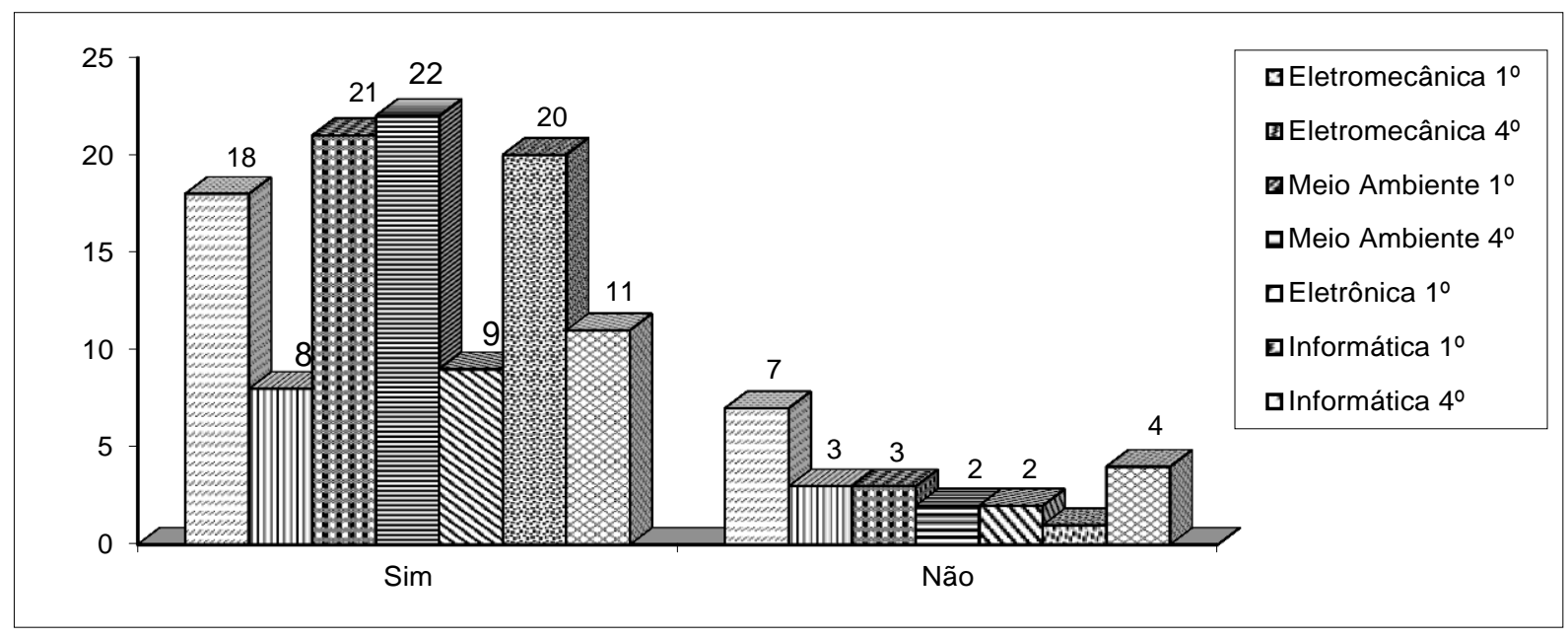

Figura 1 - Uso da matemática na resolução dos problemas do dia a dia Fonte: Dados da pesquisa

Percebe-se que foram elencadas situações mais voltadas à economia, horários e outros exemplos corriqueiros da vida diária. Todavia, alunos do quarto ano de Meio Ambiente, por terem disciplinas específicas da área que usam cálculos, citaram esgotamento sanitário, tratamento de água. Nesses casos, a Matemática entraria na representação da quantidade de produtos utilizados nas etapas e no uso da modelagem, para representar e explicar todos os fenômenos que ocorrem desde os reversíveis até as reações químicas numa sequência de relações e fórmulas. Houve aplicação dos conhecimentos matemáticos adquiridos nas disciplinas técnicas e não um estudo contextualizado no período em que os conteúdos foram explorados.

Foi, também, perguntado aos estudantes se já utilizaram a Matemática para resolver os problemas ambientais, detectando-se que 63 (cerca de 48,1\%) utilizam e 68 (cerca de $51,9 \%)$ não utilizam, conforme Figura 2. 


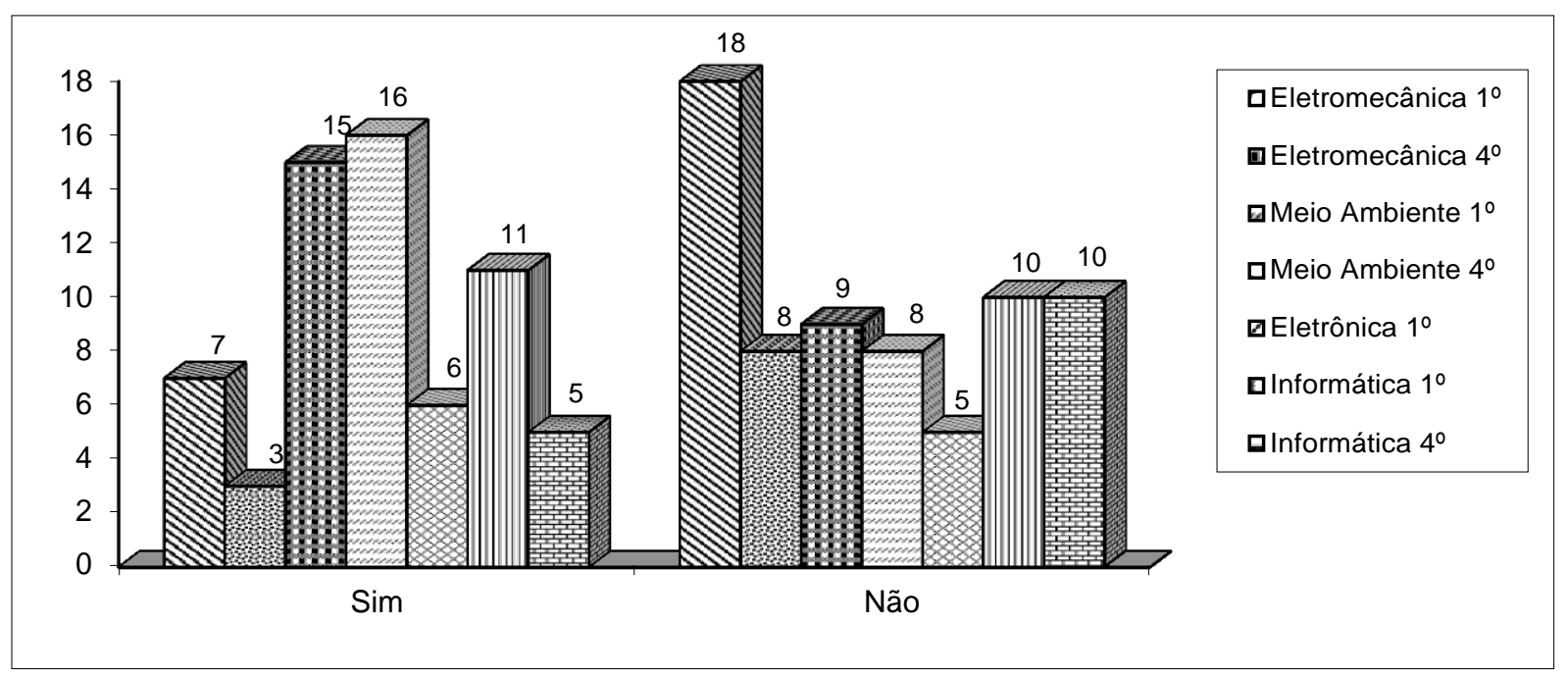

Figura 2 - Utilização da matemática para resolver problemas ambientais Fonte: Dados da pesquisa

O IFBA, Campus de Vitória da Conquista está utilizando a temática ambiental como foco das discussões, mas ainda precisa ser mais abordada pelas disciplinas como forma de atender às necessidades urgentes do contexto socioeconômico e político em que se encontra a sociedade.

A utilização da matemática como ferramenta para resolver problemas em geral, e não só os ambientais, contribui para abrir os horizontes, transformando a linguagem formal e os símbolos matemáticos em ferramentas. "Tem-se tornado cada vez maior a necessidade de que a Matemática, como disciplina escolar, acompanhe por um lado a evolução da sociedade e por outro, a evolução da ciência" (FILIPPSEN, 2003, p.2).

Diante disso, foi feita a seguinte pergunta aos alunos: quando a matemática é mais importante para você?, e obteve-se como resultado 82 (cerca de 62,6\%) pessoas que disseram que ela é importante quando entendem o conteúdo e veem aplicação na realidade; 42 (cerca de 32,7\%), quando conseguem entender a solução dos problemas; 4 (cerca de 3,1\%), quando é estudada de forma abstrata; 2 (cerca de 1,5\%), quando é estudada de forma repetitiva/ pronta/ decorada; e 1 (cerca de 0,76\%) não respondeu, como é apresentado no gráfico 3. A maioria percebe que a matemática está presente no seu cotidiano e que, conforme Fonseca (2008, p. 17), "os fenômenos ou fatos podem explicar a sistematização dos conteúdos matemáticos", ou seja, ver a aplicação dos mesmos num contexto mais amplo. 


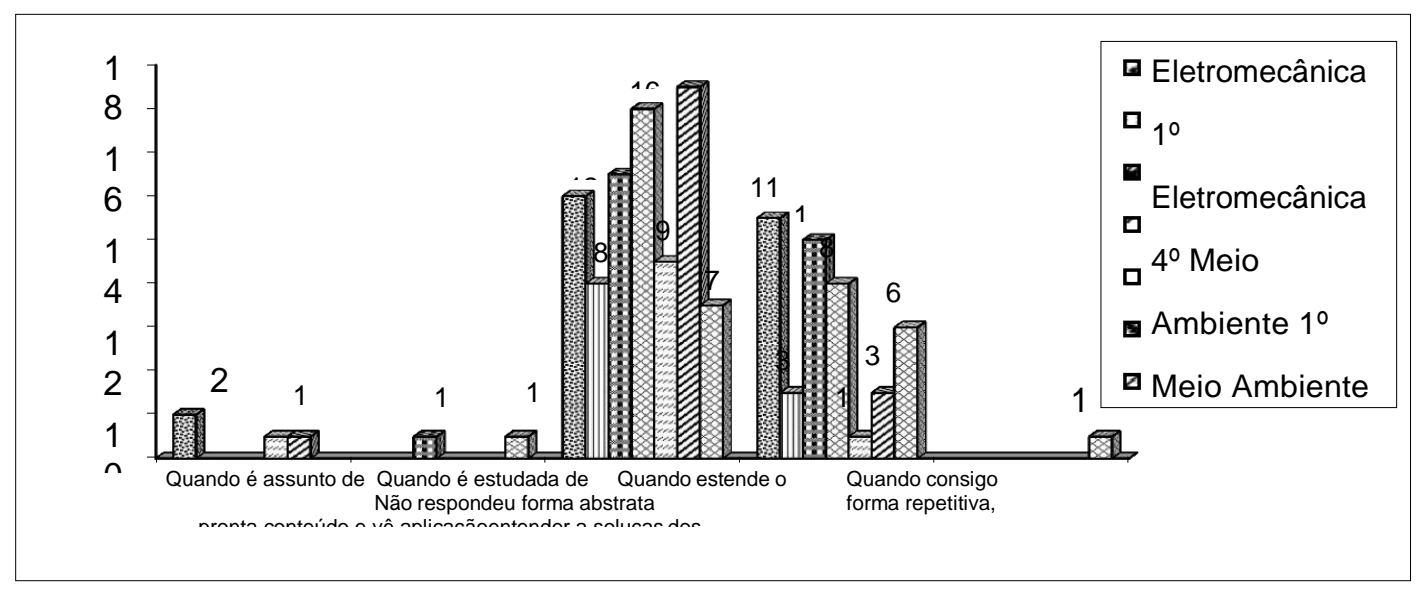

Figura 3 - Quando a Matemática é importante Fonte: Dados da pesquisa

Diante de tais considerações, conclui-se que, para o aluno, é importante questionar a respeito do conteúdo aplicado ao cotidiano para que ele possa associar, construir, comparar e, finalmente, chegar a uma conclusão. Nesse sentido, há necessidade de seleção de conteúdos e um trabalho de contextualização dos mesmos para que esses sujeitos tenham o êxito esperado pelo ensino e pela aprendizagem da Matemática.

O aluno foi indagado: o que acha mais importante trabalhar na Matemática?

Apenas 59,54\% dos alunos (78 deles) acreditam que é significativo trabalhar conteúdos voltados à realidade. Os alunos das primeiras séries de Meio Ambiente, Informática e Eletromecânica e da quarta série de Meio Ambiente enxergam que o cotidiano constitui uma grande fonte de recursos para explicar os conceitos matemáticos. O restante, conforme gráfico 4, se distribuiu da seguinte forma: 18 (cerca de 13,74\%) preferem que seja trabalhado só o conteúdo da disciplina, outros 18 (cerca de 13,74\%) só conteúdos voltados ao vestibular, 16 (cerca de 12,2\%) só temas abstratos voltados aos conteúdos (práticas) e 1 considera tudo relevante (cerca de $0,76 \%$ ). 


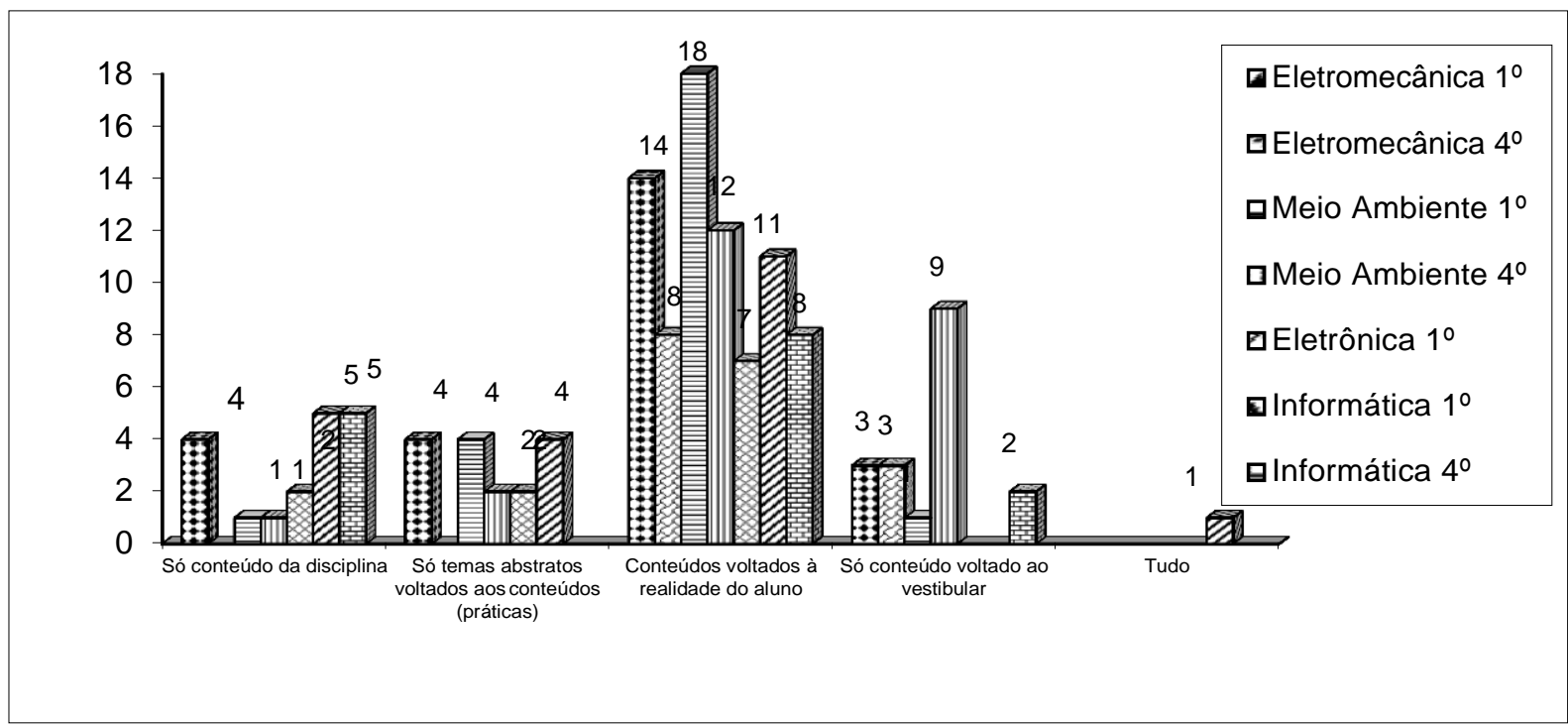

Figura 4 - O que é mais importante se trabalhar na Matemática Fonte: Dados da pesquisa

Diante das últimas considerações, percebe-se que, para o aluno, os conteúdos se tornariam mais fáceis quando aplicáveis à realidade mais próxima. De fato, torna-se significativo e mais prazeroso transformar as informações em ferramentas úteis ao contexto do sujeito.

Ao estudante também foi perguntado: qual assunto você mais discute nas aulas de Matemática?

As opções de resposta para essa pergunta foram: a) temas políticos; b) temas econômicos; c) temas sociais; d) temas ambientais; e) todos os citados e f) nenhum deles.

O resultado, apontado na Figura 5, foi: 1 indivíduo discute temas ambientais (cerca de $0,76 \%$ ); 4 discutem temas políticos (cerca de 3,05\%); 10, temas sociais (cerca de 7,63\%); 42, temas econômicos (cerca de 32,06\%); 48, nenhum dos citados (cerca de 36,64\%) e 22 discutem todos os citados (cerca de 16,79\%). Isso significa que há uma diversidade de temas que são debatidos durante as aulas de Matemática, mas não se pode deixar de considerar que hoje os temas se entrelaçam. Enfatizando essa situação, Souza e Roseira (2010) falam que o conhecimento matemático precisa ser abordado pelas várias dimensões do mundo real: cultural, socioeconômica e política. 


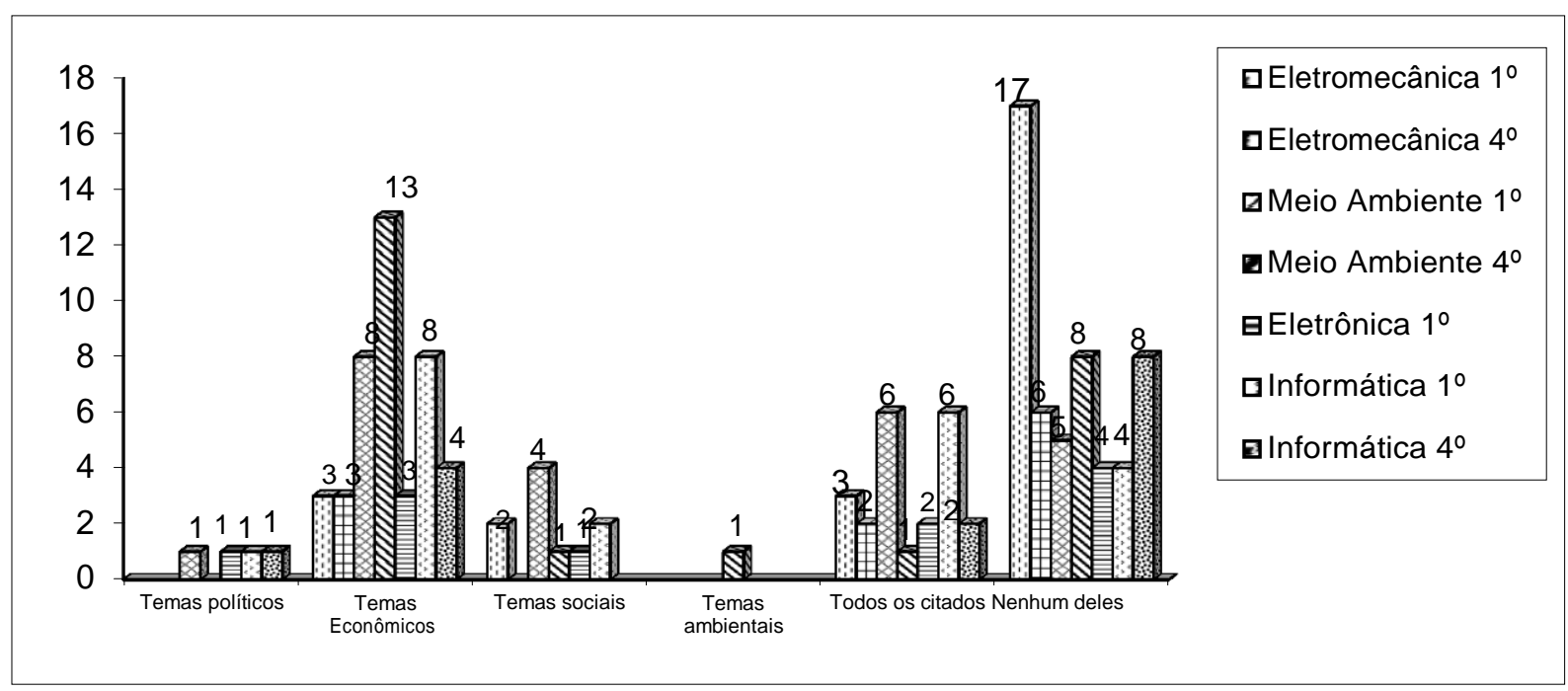

Figura 5 - Assunto mais discutido nas aulas de Matemática Fonte: Dados da pesquisa

Os temas econômicos são mais enfatizados nas aulas pelo fato de apresentarem mais proximidade com a matemática (exigem mais cálculo) e se torna mais cômodo para os professores direcionarem essa temática.

O percentual de estudantes que não discutem nenhum dos temas propostos na pergunta, durante as aulas, é alto. Para eles, as aulas são meramente transmissão continuada de assuntos. Fato que sugere uma prática pedagógica que integre todas as questões: socioeconômicas, políticas, culturais, com uma vertente para os problemas ambientais. É importante considerar que a discussão de outros temas nas aulas de Matemática dá significado aos conhecimentos a serem abordados, porém é necessário que haja correlação entre os conceitos adquiridos e a vivência dos indivíduos de forma a compreender e a transformar o contexto. Essa ideia no ambiente matemático ultrapassa o espaço da sala de aula com suas técnicas e símbolos, ou seja, os conhecimentos, os conceitos e procedimentos matemáticos são compreendidos em suas dimensões socioeconômicas, políticas, históricas e culturais, mesmo se tratando de uma ciência de caráter abstrato.

Discutir, por exemplo, a respeito do crescimento econômico significa dizer que as atividades humanas, segundo Capra (2005), estão causando danos irreversíveis. Esse caso é apenas para mostrar que é possível buscar na matemática possíveis soluções para diversos problemas. A educação precisa acompanhar o surgimento de novas tecnologias e as transformações do mundo contemporâneo, pois o aluno precisa "compreender a cidadania como participação social e política" (OLIVEIRA, 2006, p.24). Nessa nova vertente 
educacional, os cidadãos são capazes de desenvolver capacidades de pesquisar e de criar, em substituição ao velho sistema de memorização.

"A educação - um campo altamente sensível às novas demandas e temáticas sociais - incorpora a preocupação ambiental em seu universo propriamente educacional, transformando-a em objeto da teoria e prática educativa" (CARVALHO, 2001, p.189).

Para executar tais mudanças, o sistema educacional precisa passar por transformações em sua estrutura e se fundamentar, segundo Capra (2008), na alfabetização ecológica que significa muito mais do que educação ambiental, sendo o alicerce da transformação da reforma escolar. As bases tecnológicas da matemática, por exemplo, precisam se estruturar e se adequar às novas exigências do alunado e do próprio sistema que está influenciando, cada vez mais, as discussões em torno dos problemas ambientais.

De acordo com Lopes (2002, p.391) “a aprendizagem contextualizada é associada, nos PCNEM, à preocupação em retirar o aluno da condição de espectador passivo, em produzir uma aprendizagem significativa e em desenvolver o conhecimento espontâneo em direção ao conhecimento abstrato",ou seja, é preciso desenvolver a construção do conhecimento por meio do contato com a realidade.

Esse contato facilita a aprendizagem do aluno, no tocante à assimilação dos conceitos matemáticos. A diversificação do uso de metodologias, por sua vez, contribui para que o aluno alcance o real, proporcionando a ele a construção do conhecimento de maneira concreta e o desenvolvimento de habilidades e de várias aplicações. Uma delas é o projeto interdisciplinar que trabalha com diversas disciplinas e envolve vários professores com ritmos e interesses diferenciados, tornando esse tipo de atividade ainda mais interessante e cooperativo, pois favorece um ambiente de trabalho onde interagem todos os envolvidos (discentes e docentes), instigando diversas discussões.

Aos alunos foi perguntado se julgam conveniente os professores trabalharem juntos, 94 deles disseram que sim (cerca de 71,8\%); 4 (cerca de 3,05\%), não; 32 (cerca de 24,4\%), depende da situação; e 1 não respondeu (cerca de 0,76\%), conforme mostra a Figura 6. 


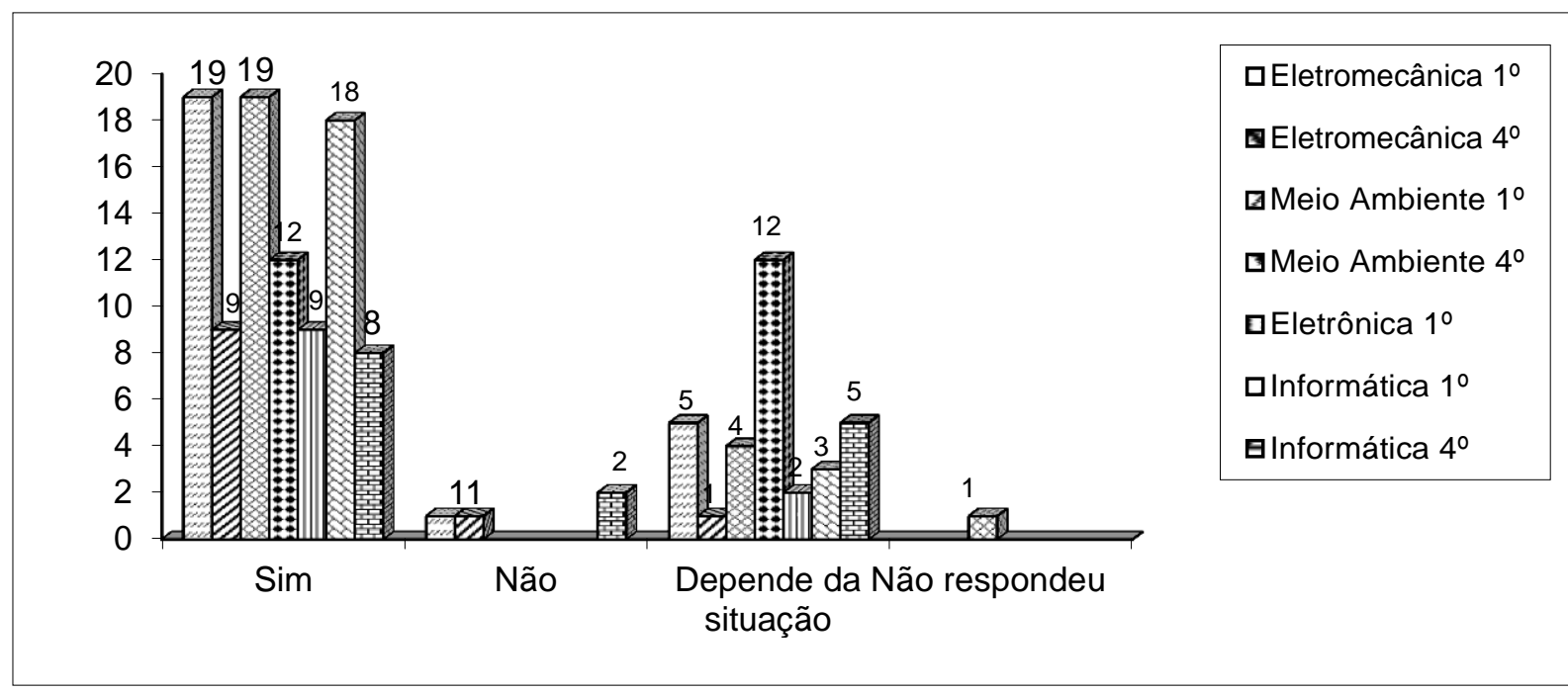

Figura 6 - Preferência do aluno pelo trabalho dos professores em conjunto Fonte: Dados da pesquisa

Na Figura 6, observa-se que os alunos do 1o ano de Meio Ambiente, Eletromecânica e Informática responderam que é importante relacionar o saber de uma disciplina com o das outras como uma maneira de aumentar as informações e enriquecer o conhecimento adquirido e aplicado ao contexto social. Na justificativa de tal pergunta, os alunos do 10 ano de Eletromecânica justificaram: "Nos ajudam mais a assimilar assuntos" $\left(A_{1}\right)$. "Um pode ajudar o outro a passar melhor os conhecimentos" $\left(A_{2}\right)$. "Estimula a coletividade" $\left(A_{3}\right)$.

De fato, para o aluno, nesse tipo de trabalho os professores se engajam, trocando experiências, e o resultado, em grande parte, é satisfatório. O estudante trabalha com prazer, mostra sua criatividade e constrói seu conhecimento por meio da troca de ideias com seus pares.

Na turma da 4a série, a resposta não mudou muito: "Para fazer pontes entre áreas distintas" $\left(A_{4}\right)$. "Integração é uma forma de dinamizar o trabalho" $\left(A_{5}\right)$.

Na turma da primeira série de Meio Ambiente, os alunos justificaram: "Um trabalho realizado coletivamente resulta em mais resultados, atinge objetivos com mais eficiência" $\left(A_{6}\right)$. "Só confirma o fato de que as disciplinas estão interligadas, e juntas, podem debater muitos alunos e dessa forma, o conhecimento aplicado é mais completo" $\left(A_{7}\right)$.

Esse grupo enfatiza a aprendizagem como principal objetivo da atividade em grupo. Outro disse que depende da situação e justificou: "Dependendo do projeto, às vezes uma matéria atrapalha a outra" $\left(A_{8}\right)$. Esse aluno é a favor de que os professores trabalhem juntos. Contudo, os educadores precisam construir e discutir a ideia para perceber se atingirá o 
objetivo da atividade, para não constituir apenas mais um trabalho facilitador do ensino e da aprendizagem.

Os alunos veteranos do Curso de Meio Ambiente (4⿳亠口了 série) responderam: "Estimula a participação dos alunos" $\left(A_{g}\right)$. "Quando conhecimentos diferentes se juntam, tudo fica mais fácil pra entender, potencializa as capacidades cognitivas discentes" $\left(A_{10}\right)$.

Os alunos expuseram que se motivam mais nesse tipo de dinâmica, pois discutem diversos temas e estimulam a aprendizagem dos mesmos. Um aluno dessa turma respondeu que depende da situação: “Algumas não gostam de aderir às regras de grupo" $\left(A_{11}\right)$.

Essa fala trata do comprometimento dos professores e das matérias envolvidas, pois, em alguns casos, os responsáveis pelas disciplinas não se envolvem ou não planejam o projeto, ficando o trabalho desconectado dos demais.

Os alunos da primeira série de Informática justificaram: "Prende a atenção do aluno" $\left(A_{12}\right)$. "Melhor aproveitamento/aprendizagem" $\left(A_{13}\right)$.

Na opinião desse grupo, o trabalho coletivo contribui para um melhor desempenho escolar. Os alunos veteranos desse curso disseram: "Interligar as matérias facilita o aprendizado" $\left(A_{14}\right)$. "As aulas passam a ser interativas" $\left(A_{15}\right)$.

Percebe-se que a visão dos alunos (1a ou 4ạ) é a mesma: foca os conteúdos das disciplinas na realidade e estimula o discente a se interagir nas atividades.

Na 1a série de Eletrônica, as opiniões ficaram parecidas com as demais: "Há uma absorção melhor dos conteúdos" $\left(\mathrm{A}_{16}\right)$. "Interação de disciplinas e maior entendimento dos alunos em diferentes assuntos" $\left(A_{17}\right)$.

Na pesquisa de Milanezi (2006, p.96), um aluno abordou a respeito da importância da atividade interdisciplinar quando disse que "é um trabalho em que não há uma matéria apenas para ser trabalhada". Essa fala traduz as colocações que os estudantes do IFBA fizeram, no sentido de envolver várias áreas do saber na mesma discussão.

Esses comentários servem de base para a reflexão no que se refere às mudanças do ensino e da aprendizagem: bases tecnológicas, metodologias utilizadas pelos professores. A didática empregada por eles não se adequa mais às necessidades e exigências do atual contexto social.

Como o aluno de hoje é ativo, acaba exigindo e gostando que o professor traga novidades para o espaço da sala de aula, que seja inovador na dimensão de 
procedimentos e atitudes. Segundo as Orientações Curriculares para o Ensino Médio Ciências da Natureza, Matemática e suas Tecnologias, "o aluno constrói conhecimento com significado, nisso se identificando com as situações que the são apresentadas, seja em seu contexto escolar, seja no exercício de sua plena cidadania" (BRASIL, 2008, p.83).

Para o professor, não existe uma receita pronta de técnicas eficazes para se atingir as metas interdisciplinares. $O$ docente precisa saber o momento certo de combinar o conteúdo

com a metodologia a ser aplicada em sala de aula, pois o importante para os sujeitos do ensino e da aprendizagem é o aumento das informações que são traduzidas em saber social.

Não basta juntar as disciplinas por áreas afins ou por assuntos e realizar uma atividade. É necessário um estudo profundo sobre de um tema que esteja ligado ao contexto mais próximo do aluno para que seu conhecimento seja transformado em saber social e de real significância para ele.

\section{$4 \quad$ Considerações Finais}

O ensino de Matemática no IFBA, campus de Vitória da Conquista, garante a inserção social do educando. Essa educação integra o saber e o fazer, a ação e reflexão crítica sobre a ação, gerando um processo de constante valorização do conhecimento do aluno.

Os alunos utilizam a Matemática para resolver os problemas do dia a dia. Só que apenas os da quarta série do Curso de Meio Ambiente apresentam aplicação em situações mais amplas e de caráter mais social. Nesse caso, houve a transformação da linguagem formal e dos símbolos matemáticos em ferramentas mais precisas, que abriram os horizontes para contextos complexos.

Tem-se a convicção de que a Matemática precisa acompanhar a evolução social e da ciência, uma vez que as exigências em torno do cidadão estão cada vez mais crescentes no que se refere à solução dos problemas.

Em relação aos aspectos ambientais, os alunos desse mesmo curso são os que mais aplicam a Matemática como ferramenta para solucioná-los, em virtude das disciplinas técnicas que utilizam os saberes matemáticos. Os demais discentes utilizam tais saberes, mas com outro foco. Isso se deve ao fato de que as discussões a respeito das questões ambientais não são constantes, limitando-se aos momentos em que se realiza alguma 
atividade que exija pesquisa.

Quando há aplicação do conteúdo matemático, o aluno busca soluções, repensa a realidade e utiliza os conhecimentos que já possui. Esse fato será possível mediante a interação do professor, aluno e realidade social.

Os sujeitos desse estudo desejam que o ensino da Matemática seja repensado, que o professor reflita se as práticas pedagógicas já existentes acompanham o progresso e as exigências do mundo real, mesmo porque esses discentes já se despertaram para a importância da contextualização do conteúdo.

Diante disso, faz-se necessária a aplicação das técnicas interdisciplinares como forma de associar os diversos saberes, tendo o cotidiano como uma grande fonte de recursos para explicar os conceitos. Os alunos da instituição aqui tratada apreciam essas atividades. Nelas, acabam assimilando mais informações que serão transformadas em conhecimento útil à sua realidade, e há até uma redução das dificuldades de abstração dos conteúdos matemáticos.

Ao tomar a realidade como objeto de discussão, o aluno analisa a sua postura como cidadão. A inclusão dos problemas socioeconômicos, políticos e culturais, notadamente os ambientais, no currículo e nas atividades escolares expõe a importância dos diversos conteúdos matemáticos. No caso específico do instituto, os alunos são conscientes da importância da proximidade com a problemática ambiental, só que a realização de trabalhos precisa aumentar para que esses indivíduos criem valores de sustentabilidade econômica e sociocultural, e exerçam seus papéis de cidadãos ecológicos.

Diante do exposto, é essencial a continuidade da pesquisa no tocante ao tempo de discussão da temática ambiental no campus, para garantir a missão do instituto que é de formar indivíduos atuantes e críticos, com o objetivo de contribuir para o desenvolvimento sustentável.

\section{Referências}

ANDRADE, J. de; HUCK, R.; SOARES, L. F. de A. Identidade cultural no Brasil. São Paulo: A9, 1999.

ANTUNES, C. As inteligências múltiplas e seus estímulos. 16ed. Campinas: Papirus, 1998.

BICUDO, M. A. V. Possibilidades pedagógicas. In: (Org.). Filosofia da educação matemática: fenomenologia, concepções, possibilidades didático-pedagógicas. São Paulo: UNESP, 2010. p.213-223. 
BRASIL. Ministério da Educação (MEC), Secretária de Educação Básica. Orientações curriculares para o ensino médio: ciências da natureza, matemática e suas tecnologias. Brasília: MEC, 2008.

BRASIL. Ministério da Educação (MEC), Secretaria de Educação Média e Tecnológica (SemTec). PCN + Ensino Médio: orientações educacionais complementares aos parâmetros curriculares nacionais - ciências da natureza, matemática e suas Tecnologias. Brasília: MEC/SemTec, 2000. Disponível em: <http://portal.mec.gov.br/seb/arquivos/pdf/ CienciasNatureza.pdf>. Acesso em: 18 ago. 2011.

CAPRA, F. Alfabetização ecológica: o desafio para a educação do século 21. In: TRIGUEIRO, A.(Coord.). Meio Ambiente no século 21: 21 especialistas falam da questão ambiental nas suas áreas de conhecimento. 5ed. Campinas: Armazém do Ipê, 2008. p.19-33.

CAPRA, F. As conexões ocultas: uma ciência para uma vida sustentável. Tradução Marcelo Brandão Cipolla. São Paulo: Cultrix, 2005.

CAPRA, F. A teia da vida. São Paulo: Cultrix, 1996.

CARVALHO, I. C. de M. A invenção do sujeito ecológico: sentidos e trajetórias em educação ambiental. 2001. 411f. Tese (Doutorado em Educação) - Faculdade de Educação, Universidade Federal do Rio Grande do Sul. Porto Alegre, 2001. Disponível em:

<http://www.reasul.org.br/mambo/files/tese_isabelcarvalho.pdf>. Acesso em: 12 out. 2011.

CODATO, L. A. B.; NAKAMA, L. Pesquisa em saúde: metodologia quantitativa ou qualitativa?.

Revista Espaço para a Saúde, Londrina, v.8, n.1, p.34-35, dez. 2006. Disponível em: <http://www.ccs.uel.br/espacoparasaude/v8n1/v8n1_artigo_6_nota.pdf>. Acesso em: 31 ago. 2011.

CRUSOÉ, N. M. de C. Interdisciplinaridade: representações sociais de professores de matemática. Natal: EDUFRN, 2009.

D’AMBRÓsıO, U. Educação matemática: da teoria à prática. Campinas: Papirus, 1996. (Coleção Perspectivas em Educação Matemática).

DIAS, G. R. Ecopercepção: um resumo didático dos desafios socioambientais. São Paulo: Gaia, 2004.

FILIPPSEN, R. M. J. Educação matemática e educação ambiental: educando para o desenvolvimento sustentável. [S.I.]: Universidade Luterana do Brasil, 2003. Disponível em <http://www.liberato.com.br/upload/arquivos/0131010716351516.pdf>. Acesso em: 24 nov. 2010.

FONSECA, L. S. da. Ensaios de educação matemática para o ensino médio. Aracaju: Info Graphics,

2008. 
LAUDARES, J. B. Educação matemática e educação tecnológica - o tratamento da matemática em cursos tecnológicos da PUC Minas. In: ENCONTRO NACIONAL DE EDUCAÇÃO MATEMÁTICA, 8, 2004, Recife, Anais... São Paulo: Sociedade Brasileira de Educação Matemática - $\quad$ SBEM, 2004. p.1-17. Disponível em: <http://www.sbem.com.br/files/viii/pdf/04/CC00991350600.pdf>. Acesso em: 29 mai. 2014.

LEITE, M. B. F.; FERREIRA, D. H. L.; SCRICH, C. R. Explorando conteúdos matemáticos a partir de temas ambientais. Ciência \& Educação, Bauru, v. 15, n. 1, p. 129-138. 2009. Disponível em: <http://www.scielo.br/pdf/ciedu/v15n1/v15n1a08.pdf>. Acesso em: 20 ago. 2011.

LOPES, A. C. Os parâmetros curriculares nacionais para o ensino médio e a submissão ao mundo produtivo: o caso do conceito de contextualização. Educ. Soc. Campinas, v. 23, n. 80, p.386-400, set. 2002. Disponível em: <http://www.scielo.br/pdf/es/v23n80/12938.pdf>. Acesso em: 28 ago. 2011.

LUCK, H. Pedagogia interdisciplinar: fundamentos teórico-metodológicos. 17ed. Petrópolis: Vozes, 2010.

MILANEZI, P. L. A participação da Matemática em práticas pedagógicas interdisciplinares. 2006. 129f. Dissertação (Mestrado em Educação) - Universidade Federal de Minas Gerais. Belo Horizonte, 2006. Disponível em: <http://www.bibliotecadigital. ufmg.br/dspace/bitstream/1843/FAEC-85TQ84/1/1000000614.pdf>. Acesso em: 04 out. 2010.

MITCHELL, D. B. A philosophical analyssis of David Orr's theory of ecological literacy: biophilia, ecojustice and moral education in middle school learning communities. 2009. $71 \mathrm{f}$. Thesis (Graduate Faculty) - University of Georgia. Athens, 2009. Disponível em: http://athenaeum.libs.uga.edu/bitstream/handle/10724/11417/mitchell_debra_b_200905_ ma.pdf?sequence=1. Acesso em: 31 mai. 2012.

MORETTO, V. P. Planejamento: planejando a educação para o desenvolvimento de competências. 6ed. Petrópolis: Vozes, 2010.

NICOLLIER, V.; VELASCO, F. G. C. A inteligência naturalista: um novo caminho para a Educação Ambiental. Revista Eletrônica do Prodema - REDE, Fortaleza, v. 2, n. 1, p. 19-44. jun. 2008.2 Disponível em: <http://www.prodema.ufc.br/revista/index.php/rede/article/viewPDFInterstitial/9/9>. Acesso em: 28 maio 2010.

OLIVEIRA, A. L. de. Educação ambiental: concepções e práticas de professores de ciências do ensino fundamental. 2006. 139f. Dissertação (Mestrado em Educação para a Ciência e o Ensino da Matemática) - Universidade Estadual de Maringá. Maringá, 2006. Disponível em: <http://www.sfiec.org.br/iel/bolsaderesiduos/Teses/Tese4.pdf>. Acesso em: 7 nov. 2011.

ORR, D. Prólogo. In: STONE, M. K.; BARLOW, Z. (Orgs.). Alfabetização ecológica: a educação das crianças para o mundo sustentável. São Paulo: Cultrix, 2006. p.9-11. 
ORR, D. What is education for? In: Context Institute Homepage. Washington, 1996. Disponível http://ecommunities.tafensw.edu.au/pluginfile.php/12139/mod_page/content/147/David\% 200rr\%20-\%20What\%20is\%20Education\%20for2.pdf. Acesso em: 29 ago, 2012.

PRADO, G. do V. T.; DAMASCENO, E. A. Saberes docentes: narrativas em destaque. In: VARANI, A.; FERREIRA, C. R.; PRADO, G. do V. T. (Orgs.). Narrativas docentes: trajetórias de trabalhos pedagógicos. Campinas: Mercado de Letras, 2007. p.15-27.

SOUZA, N. F. de; ROSEIRA, N. A. F. A contextualização no processo ensino-aprendizagem da matemática. In: JORNADA NACIONAL DE EDUCAÇÃO MATEMÁTICA, 3., JORNADA REGIONAL DE EDUCAÇÃO MATEMÁTICA, 16., 2010, Passo Fundo. Anais... Passo Fundo: UPF, 2010. p.18. Disponível em: <http://www.mat.ufrgs.br/ ppgem/contextualizacao.pdf>. Acesso em: 22 ago. 2011.

VIEIRA, V. A. As tipologias, variações e características da pesquisa de marketing. Revista da FAE, Curitiba, v. 5, n. 1, p. 61-70, jan./abr. 2002. Disponível em:

http://www.fae.edu/publicacoes/pdf/revista_da_fae/fae_v5_n1/as_tipologias_variacoes_.p df. Acesso em: 10 mar. 2014. 